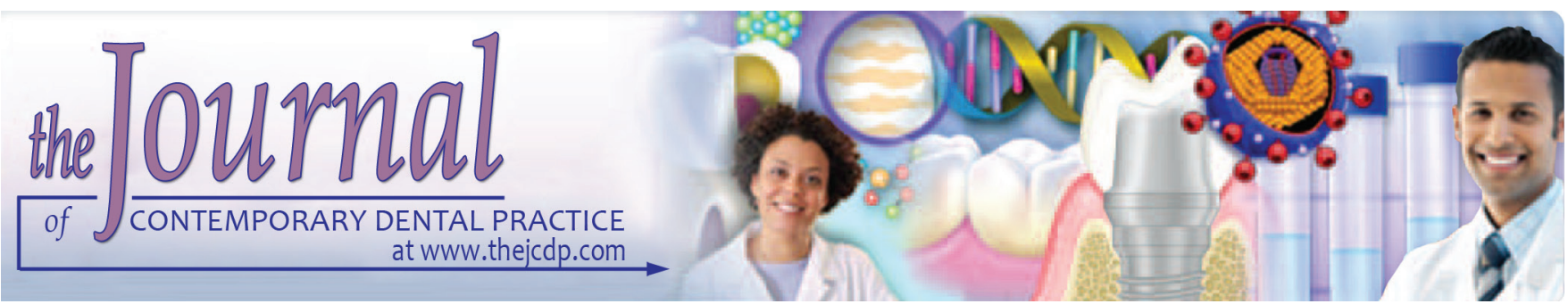

\title{
Comparison of Envelope and Modified Triangular Flaps on Incidence of Dry Socket after Surgical Removal of Impacted Mandibular Third Molars: A Double-blind, Split-mouth Study
}

${ }^{1}$ Hassan Mohajerani, ${ }^{2}$ Mohammad Esmaeelinejad, ${ }^{3}$ Mehrshad Jafari, ${ }^{4}$ Ehsan Amini, ${ }^{5}$ Somayeh P Sharabiany

\begin{abstract}
Aim: This study aimed to investigate the impact of modified triangular flap (MTF) compared with the envelope flap (EF) on the incidence of dry socket and healing degree after lowerimpacted third molar surgery.
\end{abstract}

Materials and methods: Present research was executed on 31 patients between the ages 17 and 24 years with the indication of removing impacted mandibular third molars in both sides with similar difficulty. The impacts of MTF and EF on degree of incidence of dry socket and healing on 3rd day and 1 week after surgery were recorded and investigated in a doubleblinded manner. The significant changes in mentioned indices in two groups were statistically judged using Chi-squared and Wilcoxon's statistical tests.

Results: Three patients were excluded during the survey and 28 patients (56 samples) remained. The patients' average age was 20.1 years. Totally, 19 patients were female and 11 of them had academic education. Degree of dry socket incidence in MTF group was $11.76 \%$ and it was $41.17 \%$ in EF group ( $p=0.042$ ). In the follow-up session after 3 days since the surgery, healing degree mean in MTF group was $3.16 \pm 1.5$ and it was $4.37 \pm$ 1.8 in EF group ( $p=0.112)$. In follow-up session 7 days after the surgery, mean healing degree in MTF group was $0.037 \pm$ 0.6 and it was $0.89 \pm 0.73$ in EF group $(p=0.005)$.

Conclusion: Present study indicated that application of MTF may lead to a reduction in dry socket incidence and an

\footnotetext{
${ }^{1,3-5}$ Department of Oral and Maxillofacial Surgery, School of Dentistry, Shahid Beheshti University of Medical Sciences, Tehran Islamic Republic of Iran

${ }^{2}$ Department of Oral and Maxillofacial Surgery, School of Dentistry Semnan University of Medical Sciences, Semnan, Islamic Republic of Iran

Corresponding Author: Mohammad Esmaeelinejad, Department of Oral and Maxillofacial Surgery, School of Dentistry, Semnan University of Medical Sciences, Semnan, Islamic Republic of Iran, Phone: +982166353674, e-mail: esmaeelnejad@gmail.com
}

increase of healing after 7 days since lower-impacted third molar surgeries.

Clinical significance: Reducing postsurgery complication incidences following third molar surgery is an important issue, which could easily be achieved by designing appropriate flaps.

Keywords: Dry socket, Mandible, Third molar, Wound healing.

How to cite this article: Mohajerani $H$, Esmaeelinejad $M$, Jafari M, Amini E, Sharabiany SP. Comparison of Envelope and Modified Triangular Flaps on Incidence of Dry Socket after Surgical Removal of Impacted Mandibular Third Molars: A Double-blind, Split-mouth Study. J Contemp Dent Pract 2018;19(7):836-841.

\section{Source of support: Nil}

Conflict of interest: None

\section{INTRODUCTION}

One of the main concerns of surgeons, who perform impacted teeth surgery, is incidence of dry socket after lower-impacted third molar surgery. It is estimated that incidence of this phenomenon is $20 \%$ in third molar surgery in which the patient experiences a great pain 72 hours after surgery. The pain is not relieved even by using strong sedatives. ${ }^{1}$ Occurrence of dry socket after routine extraction of the teeth is relatively rare $(2 \%)$, but it is prevalent after mandibular-impacted third molar removal $(20 \%){ }^{2}$ It is required to minimize trauma and bacterial contamination in the surgery area to prevent from dry socket syndrome, and the surgeon should perform a nontraumatic operation by cutting and setting aside the soft tissue in a sterile manner. ${ }^{3}$ Positioning a small antibiotic inside oral cavity and applying chlorhexidine mouthwash solution before and after the surgery may help to reduce the incidence of this problem. Different methods are investigated for reducing 
dry socket incidence, some of which are using antiseptic mouthwash, antifibrinolytic agents, antibiotics, steroids, antithrombosis agents, and other intraoral covers. ${ }^{4}$

In lower-impacted third molar surgeries, depending on surgeon's opinion, two kinds of flaps, envelope or modified triangular, can be used. The question is whether the application of each of those flaps has a different impact on dry socket incidence. ${ }^{5,6}$ In a study executed by Kirk et $\mathrm{al}^{7}{ }^{7}$ they stated that after using triangular flap, dry socket was observed in 2 out of 32 cases and in using EF, it was observed in 7 out of 32 cases. In another article written by Nusair and Younis, ${ }^{8}$ they stated a $4.8 \%$ prevalence of dry socket incidence of which $3.2 \%$ was observed in nonoperative tooth removal and the value was $20 \%$ in impacted third molar removal surgeries.

Considering different statistics for dry socket incidence, we decided to investigate the application of two types of flaps for lower-impacted third molar surgery and their influence on occurrence rates of dry socket.

\section{MATERIALS AND METHODS}

This clinical trial research with randomized double-blind matched prospective design was executed in the School of Dentistry, Shahid Beheshti University of Medical Sciences, Tehran, Islamic Republic of Iran, in 2016.

In this study, 56 samples ( 28 patients) were investigated such that all patients had indication of impacted wisdom molar removal, on split-mouth manner in mandible, and these teeth were located in group $C$ based on Pell-Gregory classification ${ }^{9}$ and based on Pederson criterion, they have a 7 to 10 difficulty degree. ${ }^{10}$ At the time of research, they frequently referred to the clinic and declared their agreement for cooperation in this project.

If any of following conditions were observed in patients, they were excluded from the study:

- Presence of periapical acute or chronic inflammation

- Presence of systemic problems

- Pregnancy

- Emergence of a special problem during surgery

- Follow-up missing during reexamination

- Presence of prescription for not using any certain flap

- Presence of neurological diseases

- Unreliable patients

After completing the agreement form by the participants, the difficulty degree of operation was determined based on Pell-Gregory classification and Pederson criterion, and if difficulty degree was similar in both sides and they were in group $C$ and had 7 to 10 difficulty degree, then they would receive the operation by a surgeon in the clinic. All surgeries were performed by a 3rd-year maxillofacial surgery resident under the supervision of a maxillofacial surgeon (trainer).
Modified triangular flap group (subjects group) and EF group (control group) were examined in one individual and in one jaw. The surgeon informed the examiner (evaluator) only about the area of surgery and the code of the treatment group designated to that side, and the patient and evaluator were not aware of the side to which EF is inserted and other recorded information; therefore, the study was a double-blinded one.

\section{Flap Designs}

The EF consisted of an intersulcus cut extended from the first to the second molar and continued along the external ridge of ramus. The posterior extension of the cut should be diverged outward, so that the lingual nerve is not damaged (Fig. 1).

Modified triangular flap consisted of an incision that begins from the ramus and continues up to $2 \mathrm{~mm}$ distal to the second molar and it continues downward ending in buccal vestibule (Fig. 2).

\section{Surgical Procedure}

First conventional inferior alveolar nerve block was performed by the surgeon by injecting two cartridges of $1.8 \mathrm{cc}$, lidocaine $2 \%$, and epinephrine $1.80,000$. Then, by a full mucoperiosteal EF in control side and MTF in the subject side, the bone was exposed (Fig. 3). By using a surgical handpiece (NSK, Nakanishi Inc., Japan) and a round bur (Hager and Meisinger $\mathrm{GmbH}$, Germany) with simultaneous washing with normal sterile saline, the bone was removed, and the tooth loosened and extracted with the help of an elevator. After extracting the teeth, the dental cavities were examined to make sure that no

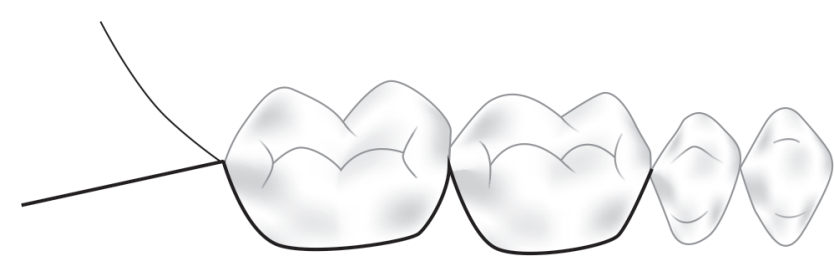

Fig. 1: Schematic design of EF

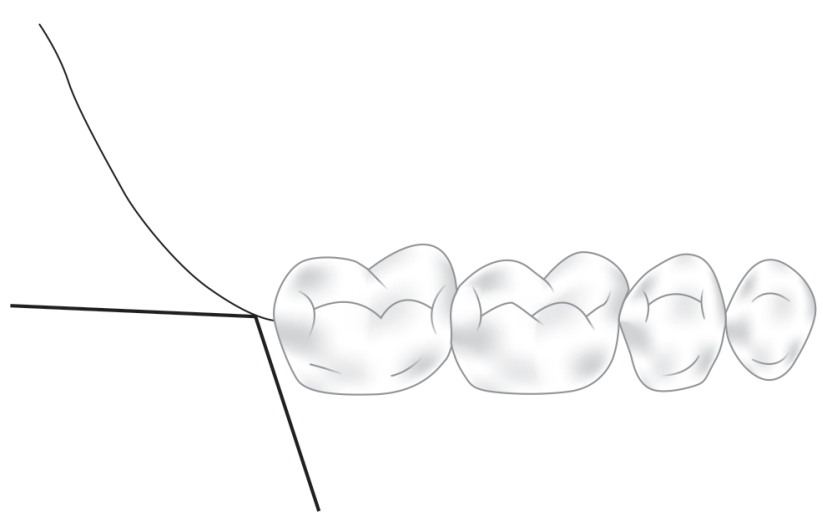

Fig. 2: Schematic design of MTF 


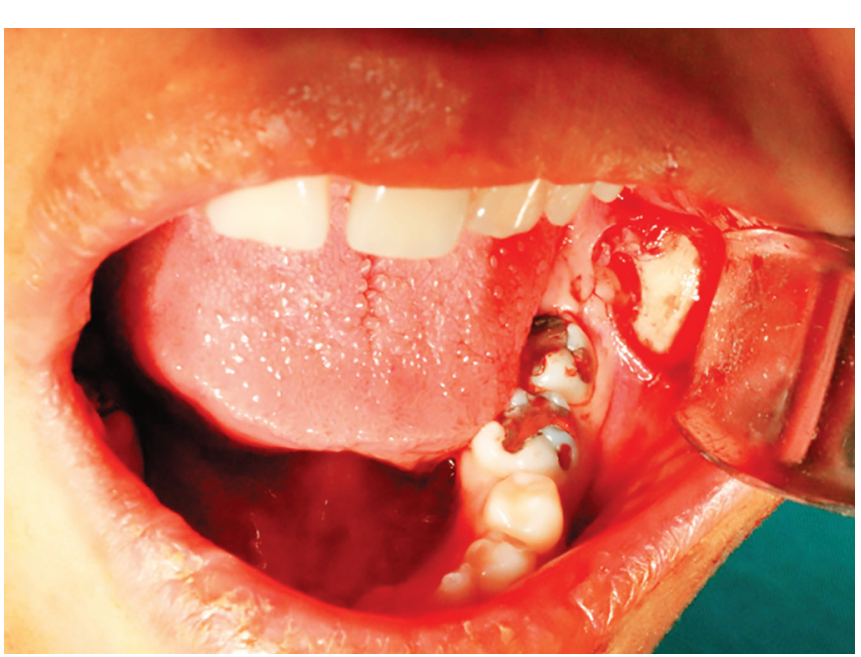

Fig. 3: Retracted MTF for surgical extraction of left mandibularimpacted third molar

follicle and tooth parts remained. The cavity was washed with 20 cc sterile normal saline, and then mucoperiosteal flaps of both the sides were turned over and closed with simple, interrupted and nonresorbable stitches.

All patients were given amoxicillin ( $500 \mathrm{mg} / 8$ hours) for 7 days and codeine/acetaminophen $(10 \mathrm{mg} / 325 \mathrm{mg})$ every 6 hours for pain relief.

\section{Outcome Variables}

Healing degree was also rated based on a healing scale starting from 0 to 9 ( 0 means good healing, 1 to 2 means inflammation, 3 to 5 means opening of clot, 6 to 8 means opening of lesion with or without infection, and 9 means lack of any healing), and it was investigated by an evaluator 72 hours and 1 week after tooth extraction in the clinic. Those who experienced dry socket were treated immediately. The only purpose related to dry socket treatment was reduction of pain during the healing period. Incidence of dry socket and healing degree were judged based on follow-up time and treatment group (subject and control).

\section{Ethical Considerations}

Participants were informed of the purpose and design of the investigation, and signed an appropriate consent form. The procedures followed were in accordance with the ethical standards of the responsible committee on human experimentation of Shahid Beheshti University of Medical Sciences and with the Helsinki Declaration of 1975 that was revised in 2000.

\section{Statistical Analysis}

All calculations have been processed using the Statistical Package for the Social Sciences statistical software (version 20; SPSS Inc.). Descriptive statistics including

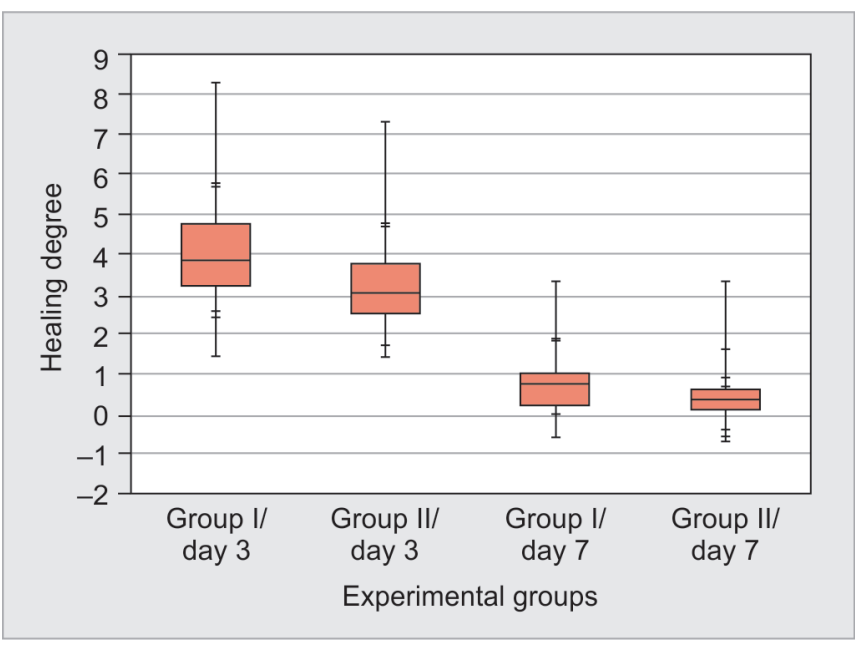

Graph 1: Box plot diagram at confidence limit of $95 \%$ healing degree in envelope and MTF after 3 and 7 days

tables and graphs have been applied to show the information. Chi-squared test and Wilcoxon signed ranks were used to determine the significant differences variables. A p-value of less than 0.05 has been considered statistically significant.

\section{RESULTS}

In the first stage of the research, statistical analysis was conducted on 31 qualified patients, of whom 3 were excluded from the study due to their poor cooperation during followup visits. The study was executed finally on 28 patients (56 samples), who had indications of both impacted mandibular third molar extraction. Average age of patients was 20.1 years (between 17 and 24 years). Nineteen of them were females and nine of them were males.

Incidences of dry socket in the control side EF and in subject group MTF (39.28\% and $10.71 \%$ respectively) were statistically significant $(\mathrm{p}=0.042)$.

Healing degree of operation area in patients is presented based on follow-up time and studied groups in Graph 1, which indicates that in follow-up session held 3 days after surgery, the average healing degree of the control group was $4.37 \pm 1.8$ and it was $3.16 \pm 1.5$ in the subject group. Wilcoxon signed rank test indicated that this difference was not significant $(\mathrm{p}=0.112)$.

In a follow-up session held 7 days after the surgery, healing degree in control group was $0.89 \pm 0.73$ and it was $0.037 \pm 0.6$ in the subjects group, which was based on Wilcoxon signed rank test. This difference was statistically significant $(\mathrm{p}=0.005)$.

Dry socket incidence and its related risk factors including smoking, bruxism history, and previous experience of dry socket, and using contraceptive pills are shown in Table 1. 
Comparison of Envelope and Modified Triangular Flaps

Table 1: Qualified patients' distribution based on personal characteristics and incidence of dry socket in them

\begin{tabular}{|c|c|c|c|c|c|c|c|c|c|}
\hline \multirow{2}{*}{ Factors } & \multirow[b]{2}{*}{ Age } & \multicolumn{2}{|c|}{ Gender } & \multirow[b]{2}{*}{ Smoking } & \multirow[b]{2}{*}{ History } & \multirow{2}{*}{$\begin{array}{l}\text { Previous } \\
\text { dry socket } \\
\text { experience }\end{array}$} & \multirow[b]{2}{*}{$\begin{array}{l}\text { Contraceptive pill } \\
\text { consumption }\end{array}$} & \multicolumn{2}{|c|}{ Education level } \\
\hline & & Male & Female & & & & & $\begin{array}{l}\text { High } \\
\text { school }\end{array}$ & $\begin{array}{l}\text { Higher } \\
\text { education }\end{array}$ \\
\hline All patients & 20.41 & 10 & 4 & 4 & 2 & 2 & 3 & 8 & 6 \\
\hline A & 20.33 & 10 & 1 & 2 & 1 & 2 & 1 & 6 & 5 \\
\hline B & 20.25 & 0 & 3 & 2 & 1 & 0 & 2 & 2 & 1 \\
\hline
\end{tabular}

A: Control group (envelope flap was used); B: Subjects group (modified triangular flap was used)

\section{DISCUSSION}

In today's modern surgeries, introduction of flap is a fundamental step along with the other steps of surgery for achieving successful therapy. Due to the presence of impacting factors and conditions in each case, selecting a suitable design is highly necessary. In intraoral surgeries, oral and maxillofacial surgeons use different flaps based on type of impaction, access degree, and opinion of surgeon. ${ }^{11,12}$ In this study, we aimed to evaluate the influence of a traditional EF and an MTF on wound healing and incidence of dry socket.

In an study conducted by Benediktsdottir et $\mathrm{al}^{1}{ }^{1}$ the risk of dry socket incidence during mandible third molar extraction among 388 patients was reported as 5.9\% (23 patients), of which $9 \%$ were female and $1.8 \%$ were male. This result indicated that the women were more vulnerable than men (5 times) to experience dry socket. In this research, it is stated that gender difference is the only significant index relating to dry socket, which has not been proven in our research. In this study, it was stated that the molars, which undergo surgery and completely or partly are placed inside the bone, such that the surgeon must extract the bone, and also the molars that are completely grown or half grown were omitted of the study. From 388 samples, 54 samples were totally impacted and 329 samples were half-impacted. Regarding the low number of impacted molars compared with the total molars for study $(7 \%)$, this statistical difference seems natural because all our samples were in group $C$ in terms of difficulty degree of operation and all were in difficult groups in terms of degree of difficulty in operation .

In a review article presented by Torres-Lagares et al, ${ }^{2}$ dry socket incidence amplitude was stated as being very common, i.e., from 1 to $70 \%$, and they said that dry socket emergence is usually expectable after extracting remaining third molars. Its incidence degree was said to be 20 to $30 \%$ of extracted molars. This value is 10 times more than that in other teeth. The above-reported results confirm our findings.

In a study performed by Singh et $\mathrm{al}^{13}{ }^{13}$ they clinically investigated dry socket in an oral health center. They reported dry socket incidence value in 4,077 patients as $2 \%$. They also stated that the area experiencing this problem greatly than other areas were mandibular second molars with $22 \%$ dry socket incidence value. The reason for difference between their results and ours could be that our samples were located in posterior mandibular and has a high difficulty degree of molars.

As mentioned earlier, the reports are very different in terms of teeth extraction methods (surgery based or nonsurgery based), age and gender of patients, the experience of surgeon, and even economic level of persons.

The positive effect of MTF on dry socket incidence reduction after mandibular-impacted third molar surgery was reported by Kirk et al. ${ }^{7}$ As a result of this study, it was proven that dry socket incidence in MTF group was less; however, it was not statistically significant.

The EF makes the surgeon have better access to the site of surgery. Furthermore, the surgeon can extend the sulcular incision from anterior area in this flap while having a wide base. Perfusion would be better and stitching easier in this case. The possible disadvantages of EF are investigated in different articles including destruction of periodontal ligament during sulcular incision around the teeth; osteoclastic activity increases during lifting of the mucoperiosteal flap leading to more bone loss, and a higher risk of wound rupture during postsurgical period. ${ }^{14,15}$

The MTF is a more conservative method than the other flaps, and induces less tissue reaction. The reason for this is that the soft tissue is lifted from the buccal of the second molar. This condition leads to easy wound closure and tension-free stitches, but it is not extendable like the $\mathrm{EF}^{5}$

The results of our study also indicate better response by the patients who received MTF than those who received the pocket one. Dry socket incidence percent in the group that received MTF was less than that in the EF group.

Nusair and Younis ${ }^{8}$ with the aim of investigation of dry socket prevalence and microfactors in Jordan Dental Educational Center showed that the dry socket prevalence is totally $4.8 \%$, and it is $3.2 \%$ in nonsurgical tooth extraction and $20.1 \%$ in surgery-based tooth extraction. The results of our research indicated that dry socket incidence was $26.47 \%$ and these values are proven earlier.

In another study executed by Blondeau and Daniel, ${ }^{16}$ they studied impacted mandibular third molars and 
postsurgery problems and its risk factors. In this article, degree of dry socket incidence of previous studies is reported with a high diversity which is from the lowest, $0.5 \%$, to the highest, $68.4 \%$, but in most studies, 5 to $10 \%$ is reported for dry socket incidence. Dry socket incidence mentioned in the study is reported as 3.6\% that is lower than $5 \%$, and the reason is due to the experience and skill of the surgeon or due to using tetracycline in the surgery area. The categorization of the impact of the molars in this study was based on IC, IIC, Pell and Gregory definitions, and, in this study, it is stated that there is a direct relationship between extracted molar impaction and emergence of postsurgery problems. The results of this study have high differences from our study results (dry socket incidence value: $26.47 \%$ ), the reason for which could be high difficulty of surgery (based on Pederson criterion in difficult group and four-point trauma rating scale in group (), and as mentioned earlier, it has a direct relationship with high incidence of postsurgery problems. In addition, antibiotic was used in this study, but we did not apply this medicine.

Oginni et al $^{3}$ clinically studied dry socket in an educational hospital in Nigeria from 1996 to 2000. In this study, 3,319 extracted teeth were studied of which 136 or $4.1 \%$ of patients experienced dry socket after molar extraction. In this article, degree of incidence of dry socket in the mandible was reported as three times that of maxilla. In our study, dry socket incidence value was $26.47 \%$ and the reason for its high difference with the above study is perhaps because of the type of molars that were included in the surgery in our study (impacted mandibular wisdom molars with high difficulty degree), while in Oginni et $\mathrm{al}^{3}$ study, all teeth were extracted in a nonsurgical manner.

In a study performed by Jakse et al, ${ }^{17}$ primary healing of lesion after mandibular third molar surgery was compared with two different flaps. They extracted 60 hidden teeth, they used EF for extracting 30 samples, and for the remaining 30 samples, they used MTF. They observed that $33 \%$ experienced wound rupture of which $10 \%$ was for those who received MTF and $57 \%$ for those who received EF. In this study, the relationship between five risk factors with healing degree was investigated with 95\% confidence coefficient and from among flap types (pocket, modified triangular), impaction degree (totally hidden or halfimpacted), surgery duration (less than 25 minutes or more than 25 minutes), smoking, and age. Only the statistical data of flap type were evidently significant.

Our results also indicate that healing degree in molars extracted by MTF is faster than that in molars extracted by EFs.

In a study performed by Krik et $\mathrm{al}_{1}^{7}$ all areas cut with MTF were able to have primary closure, while most of the lesions cut with EF could not have primary closure, and this finding confirms our results. Some of the valuable aspects of this study are that it was double blinded and splitmouthed and that all patients were operated by a single surgeon. This would increase internal generalizability of research, but would reduce external generalizability of it.

Some of the limitations of this research are replication of subjects and control groups, finding the patients having two-sided impacted third molar with similar difficulty degree (difficulty degree of 7-10 based on Pederson's criterion), and lack of cooperation by patients and their absence in follow-up sessions.

\section{CONCLUSION}

This study indicated that MTF leads to reduced incidence of dry socket and decreased healing period after mandibular-impacted wisdom molar surgery. It seems that the obtained results and different responses by patients relating to MTF compared with EF relating to dry socket and faster healing degree is due to the lower area of this flap and that the oral tissues are disturbed to a minor extent.

\section{REFERENCES}

1. Benediktsdottir IS, Wenzel A, Petersen JK, Hintze H. Mandibular third molar removal: risk indicators for extended operation time, postoperative pain, and complications. Oral Surg Oral Med Oral Pathol Oral Radiol Endod 2004 Apr;97(4):438-446.

2. Torres-Lagares D, Serrera-Figallo MA, Romero-Ruiz MM, Infante-Cossio P, Garcia-Calderon M, Gutierrez-Perez JL. Update on dry socket: a review of the literature. Med Oral Patol Oral Cir Bucal 2005 Jan-Feb;10(1):81-85, 77-81.

3. Oginni FO, Fatusi OA, Alagbe AO. A clinical evaluation of dry socket in a Nigerian teaching hospital. J Oral Maxillofac Surg 2003 Aug;61(8):871-876.

4. Sharif MO, Dawoud BE, Tsichlaki A, Yates JM. Interventions for the prevention of dry socket: an evidence-based update. Br Dent J 2014 Jul;217(1):27-30.

5. Koyuncu BÖ, Çetingül E. Short-term clinical outcomes of two different flap techniques in impacted mandibular third molar surgery. Oral Med Oral Pathol Oral Radiol Endod 2013 Sep;116(3):e179-e184.

6. Elo JA, Sun H-H, Dong F, Tandon R, Singh HM. Novel incision design and primary flap closure reduces the incidence of alveolar osteitis and infection in impacted mandibular third molar surgery. Oral Surg Oral Med Oral Pathol Oral Radiol 2016 Aug;122(2):124-133.

7. Kirk DG, Liston PN, Tong DC, Love RM. Influence of two different flap designs on incidence of pain, swelling, trismus, and alveolar osteitis in the week following third molar surgery. Oral Surg Oral Med Oral Pathol Oral Radiol Endod 2007 Jul;104(1):e1-e6.

8. Nusair YM, Younis MH. Prevalence, clinical picture, and risk factors of dry socket in a Jordanian dental teaching center. J Contemp Dent Pract 2007 Mar;8(3):53-63.

9. Yuasa H, Kawai T, Sugiura M. Classification of surgical difficulty in extracting impacted third molars. Br J Oral Maxillofac Surg 2002 Feb;40(1):26-31. 
10. Koerner KR. The removal of impacted third molars. Principles and procedures. Dent Clin North Am 1994 Apr;38(2):255-278.

11. Chen YW, Lee CT, Hum L, Chuang SK. Effect of flap design on periodontal healing after impacted third molar extraction: a systematic review and meta-analysis. Int J Oral Maxillofac Surg 2017 Mar;46(3):363-372.

12. Briguglio F, Zenobio EG, Isola G, Briguglio R, Briguglio E, Farronato D, Shibli JA. Complications in surgical removal of impacted mandibular third molars in relation to flap design: clinical and statistical evaluations. Quintessence Int 2011 Jun;42(6):445-453.

13. Singh AS, Mohamed A, Bouckaert MM. A clinical evaluation of dry sockets at the Medunsa Oral Health Centre. SADJ 2008 Oct;63(9):490, 492-493.
14. Baqain ZH, Al-Shafii A, Hamdan AA, Sawair FA. Flap design and mandibular third molar surgery: a split mouth randomized clinical study. Int J Oral Maxillofac Surg 2012 Aug;41(8):1020-1024.

15. Yolcu U, Acar AH. Comparison of a new flap design with the routinely used triangular flap design in third molar surgery. Int J Oral Maxillofac Surg 2015 Nov;44(11):1390-1397.

16. Blondeau F, Daniel NG. Extraction of impacted mandibular third molars: postoperative complications and their risk factors. J Can Dent Assoc 2007 May;73(4):325.

17. Jakse N, Bankaoglu V, Wimmer G, Eskici A, Pertl C. Primary wound healing after lower third molar surgery: evaluation of 2 different flap designs. Oral Surg Oral Med Oral Pathol Oral Radiol Endod 2002 Jan;93(1):7-12. 